\title{
PRISPEVEK URBANE GEOGRAFIJE K URBANISTIČNEMU PLANIRANJU - PRIMER UREDITVE DEGRADIRANEGA OBMOČJA TRBOVELJ
}

\author{
Naja Marot \\ Bevško 45b, SI - I420 Trbovlje, Slovenija \\ e-mail: naja.marot@guest.arnes.si
}

Pregledni znanstveni članek

COBISS 1.02

\section{Izvleček}

Dvestoletno rudarjenje je Trbovljam prineslo številne gospodarske, demografske in prostorske spremembe, ki so še posebej opazne v jugovzhodnem predelu nekdaj intenzivnega izkoriščanja premoga. S pomočjo osnovne geografske analize prostorskega, demografskega in gospodarskega razvoja, analizo javnega mnenja in strokovnih pogledov na reševanje in opisom uspešnega angleškega projekta urbane prenove smo poskušali najti učinkovit model in vsebino prihodnjega razvoja obravnavanega območja.

Kjučne besede: degradirano urbano območje, Liverpool, Trbovlje, urbana geografija, urbana prenova, urbanistično planiranje.

\section{PRACTICAL VALUE OF URBAN GEOGRAPHY IN URBAN PLANNING - CASE STUDY OF THE SOUTH-EASTERN PART OF TRBOVLJE}

\begin{abstract}
Two centuries of mining have significantly changed the town of Trbovlje in economic, social and spatial terms. This is especially evident in the south-eastern part of the town. On the basis of general geographical analysis of spatial, demographic and economic development, a query of public opinion and a survey of experts' ideas, with description of successful English urban renewal project we try to find out the most effective model and context of the future development in the area in question.
\end{abstract}

Key words: degraded urban area, Liverpool, Trbovlje, public participation, urban geography, urban planning, urban renewal. 


\section{UVOD}

Dvestoletna tradicija rudarjenja je Trbovljam prinesla številne gospodarske, demografske in prostorske spremembe, ki se najbolje odražajo v degradiranem jugovzhodnem delu Trbovelj, na območju nekdanjih dnevnih kopov (Lakonca, Bukova gora, Retje), prvih rudarskih kolonij (Ribnik, Žabjek, Nasipi) in kasneje močno industrializiranega predela. Dolgoročni prostorski plan občine (1986) celotno območje uvršča v plansko celoto sedem, za katero smo poskusili pripraviti model urbane prenove.

Za proces urbane prenove $\mathrm{v}$ Sloveniji ni ustaljenih postopkov priprave in izvedbe projektov, ampak se projekti pripravljajo ločeno glede na trenutno stanje in interese investitorjev. Vladni program strokovne in finančne pomoči za pospeševanje procesa ne obstaja, zato vse bolj prihaja do propadanja starih mestnih središč in predvsem nekdanjih industrijskih območjih, problematičnih v večjih slovenskih mestih. Zato smo kot vzorčni primer izbrali mesto Liverpool oziroma njegov jugovzhodni del Speke, nekdaj drugo najbolj degradirano okrožje v Angliji, ki je danes, po desetih letih intenzivnih prostorskih, socialnih in gospodarskih posegov, povsem preobraženo območje s svetlo prihodnostjo. V kolikor želimo, da je urbana prenova dolgoročna in učinkovita naložba je treba najprej temeljito analizirati območje, dosedanji prostorski razvoj, pregledati prostorsko dokumentacijo in veljavna določila prostorskih planov in o željah ureditev povprašati tako lokalno prebivalstvo kot strokovnjake prostorskega planiranja (Marot, 2005). Pri vsem tem lahko v veliki meri pomagajo teoretična izhodišča urbane geografije, kvantitativne metode in terensko delo, s čimer se lahko tudi geografi aktivno in enakovredno drugim strokam vključijo v urbanistično planiranje.

Jugovzhodni del Trbovelj in Črni revir sta bila za geografe zanimiva že od nekdaj. Najbolj intenzivno se je regiji posvečal Vrišer (1963). Prostorski razvoj celotnega naselja je v delu Naše Trbovlje opisala Ivančič Lebar (1999). Problematiko prenove so z različnimi idejami v svojih delih reševali Pogačnik (1996), Žilnik (2002), Špilar (2003), Jeraj (2003), Tavzelj (2003), študentje pa so se v diplomskih delih največkrat osredotočili na preučevanje posameznih prostorskih elementov. Glavno teoretično delo o degradiranih urbanih območjih je v Sloveniji izdal Koželj (1998) od tujih teoretikov smo upoštevali dela Greed (1994, 1996), Cullingworth Nadin (2002) in obsežno dokumentacijo, pripravljeno za območje Speke oziroma celotni Liverpool.

\section{ANALIZA OBMOČJA}

Ne glede na to, ali gre za terensko ali kabinetno delo, geograf v začetnih fazah vedno opravi analizo izbranega območja. V urbani geografiji in urbanističnem planiranju nas ne zanima mesto le kot celota, ampak hkrati tudi njegovi posamezni deli, ki pripomorejo $\mathrm{k}$ funkcioniranju mestnega sistema. Če želimo razumeti sedanje stanje in izdelati optimalen plan, je potrebno razumeti dosedanji razvoj območja in njegove dejavnike, zato se največkrat ločeno osredotočimo na okolje in prostor, gospodarstvo in na prebivalstvo. Prvega najbolje spoznamo s pomočjo kartografskega gradiva in terenskega dela, medtem ko se pri drugih dveh največkrat zatečemo k statističnim podatkom oziroma k izvedbi kvalitativnih metod, 
na primer intervjuja. Za lažjo izvedbo terenskega dela smo si tako v planski celoti sedem kot v Liverpoolu izbrali vzorčno območje - rudarsko kolonijo Žabjek - del krajevne skupnosti Alojz Hohkraut, ki skoraj v celoti pokriva izbrano območje.

Slika 1: Zasnova priprave modela

Figure 1: Scheme of model preparation

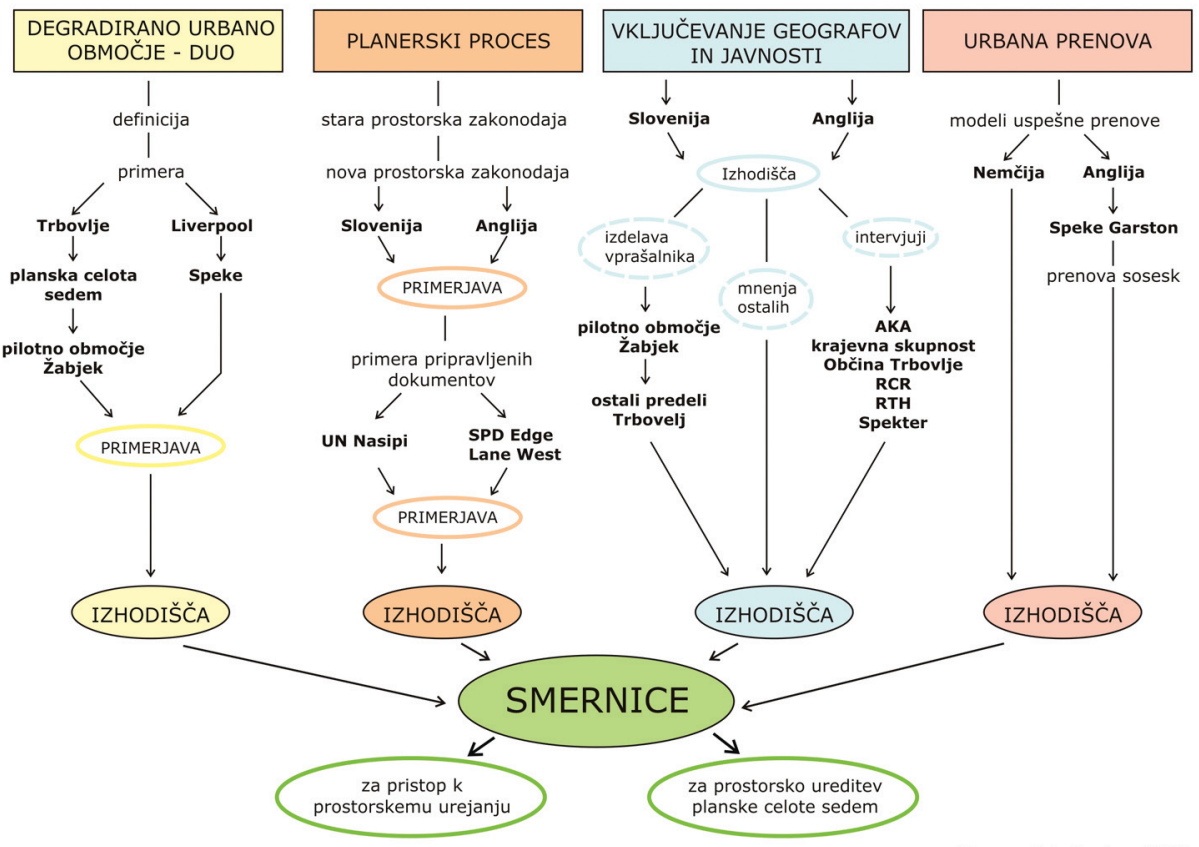

Zasnova: Naja Marot, maj 2005

Opis prostorskega razvoja izbranih območij je bil dopolnjen s popisnimi podatki popisov obdobja sprejetih dokumentov (1981, 1991, 2002/2001 - Anglija; medmrežje 4). Največji problem je bil pridobiti podatke, ki razen preko naročila niso več javno dostopni. Prav tako se izbrani kazalci razlikujejo (slovenske opredelitve, slovensko/angleške opredelitve) med posameznimi popisi. Podatki zadnjih dveh popisov niso bili zbrani v istem letu, kar zmanjša njihovo primerljivost.

Vse to smo upoštevali pri pripravi modela urbane prenove, pri čemer smo zaradi ustreznosti prenosa modela na slovenske razmere vzporedno analizirali še angleški vzorčni primer.

\section{I Prostorski razvoj in statistična analiza območja}

Planska celota sedem predstavlja začetek trboveljskega poselitvenega prostora, saj so že v srednjem veku tu nastali prvi agrarni zaselki. Pred začetkom izkoriščanja premoga in 
industrijsko revolucijo so imele takrat razložene Trbovlje 536 prebivalcev, v obdobju od leta 1870 do 1961 se je število prebivalcev (1600) povečalo kar za 1151 \% (Vrišer, 1963: 138). Zaradi nahajališč premoga pod površjem so se posledice rudarjenja najprej občutile na jugovzhodnem območju - uničena naselja s pripadajočimi zemljišči (Ivančič Lebar, 1999) in se z leti samo še stopnjevale.

Speke tako kot planska celota sedem leži ob jugovzhodnem vstopu v mesto. Njegov začetek sega v 20. leta 20. stoletja, ko so mestni urbanisti nekdaj ribiško vas določili kot območje preselitve prebivalstva iz prenatrpanega mestnega središča v novo, načrtno zgrajeno sosesko s pozneje razvito bazično industrijo. Slednja se je vse od 60. letih naprej skupaj s pomorskim prometom borila za preživetje, danes pa se je s pomočjo razvojnih programov v veliki meri že prestrukturirala.

Delež prebivalcev območja glede na mesto znaša 11 (2055) oziroma 2 (9098) \%, gostota poselitve je v obeh predelih visoka $\left(654 / 4292 \mathrm{preb} / \mathrm{km}^{2}\right)$. Demografska slika je neugodna, saj je prebivalstvo v obdobju od leta 1981 do 2001 upadlo za eno petino oziroma eno tretjino, pri čemer je mladih za $37 \%$ manj, medtem ko delež starejših na trboveljskem območju prav tako pada (26 \%), na liverpoolskem pa močno narašča (59 \%). Povprečna starost znaša 38/37 let. V Žabjeku je od začetka vojne za Slovenijo zaradi nesoglasij med prebivalci nekdanjih jugoslovanskih republik problematična narodnostna sestava - delež Neslovencev je okrog 10 \%. Poleg etničnih konfliktov so problematična še manjša kriminalna dejanja, droge, alkohol in brezdomci. Prevladujejo nizko kvalificirani delavci (okrog $60 \% / 53 \%$ ) in slaba pismenost (38 \% - Speke; Popis 2002 2005; Ward ... 2004; South ... 2002 ).

\section{Slika 2a in 2b: Degradirano urbano območje Speke v Liverpoolu (Naja Marot)}

Figure $2 a$ and 2b: Speke - Degraded urban area in Liverpool (Naja Marot)

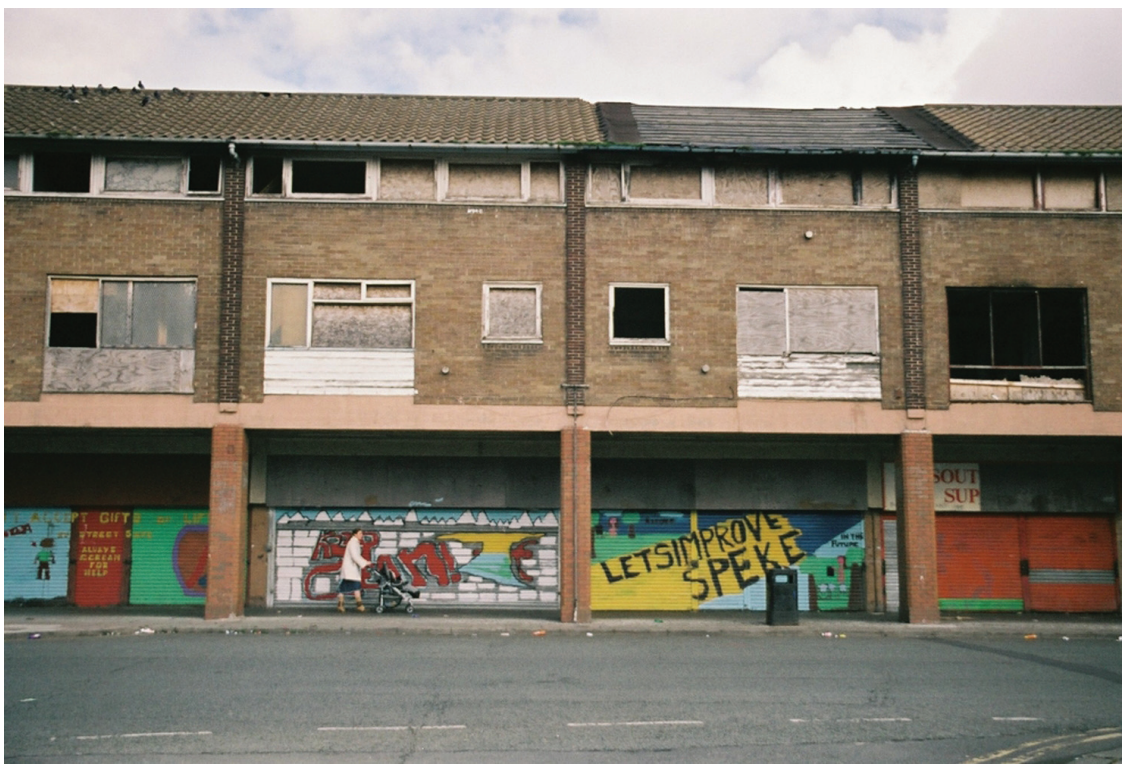




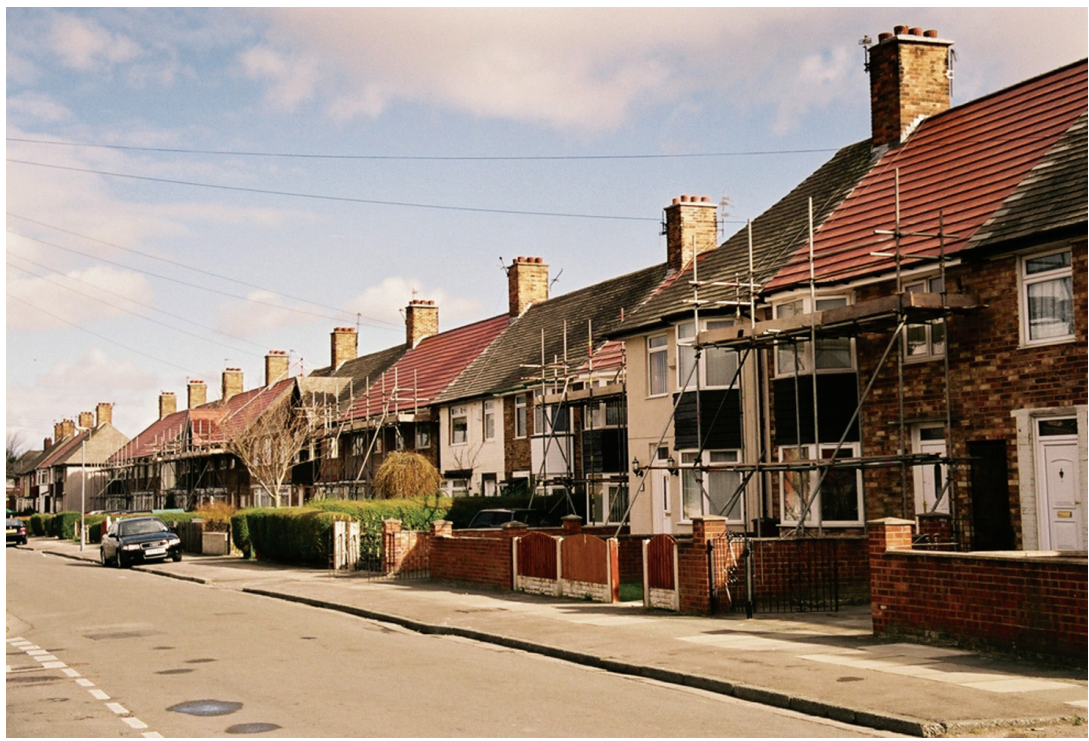

Na obeh območjih prevladujejo večstanovanjski objekti, v Trbovljah (77 \%) so to dotrajane rudarske kolonije, v Speku z 72 \% vrstne hiše. Kvaliteta bivanja je slaba, saj večina stanovanj nima centralnega ogrevanja ( $57 \% / 44 \%$ ), brez kopalnice in toaletnih prostorov jih je $16 \%(0 \%)$, infrastruktura je neurejena, prav tako odlaganje odpadkov. Stanovalci so največkrat najemniki ( $94 \% / 66 \%$ ) socialnih in kadrovskih stanovanj. V Speku primanjkuje storitev, slaba je oskrba ostarelega prebivalstva.

Za obe območji obstajajo številna zaničevala poimenovanja, na primer Bejrut za Speke, prav tako so razlike med dojemanjem soseske s strani domačinov in ostalega prebivalstva, ki se je najraje izogiba (Hall 2003). Zaradi izkopov, posledično denudacije in erozije, je prišlo do ugrezov, razpok, plazov, zdrsov in nastanka depresij (Špilar, 1994; Gabrijel, 2003). Obe območji sta močno onesnaženi: previsoke koncentracije $\mathrm{SO}_{2}$-ja, prah, požgane rastline, težke kovine v prsti in hrup (Vidergar-Gorjup, Batič 1999).

Na podlagi obravnavnih značilnosti lahko območji razglasimo za degradirani urbani območji (Koželj, 1998) z zmanjšano vrednostjo zemljišč, stavb, naprav, za kateri je nujno potrebna vzpostavitev ponovne rabe in dejavnosti, v kolikor ne želimo, da postaneta fizična in funkcionalna ovira za razvoj mesta.

\subsection{Analiza dosedanjih planov}

Pri planiranju prostorskega razvoja določenega območja moramo upoštevati tudi dotedanje dolgoročne/kratkoročne regionalne in občinske prostorske plane, saj so predstavljali podlago za dosedanje prostorske posege oziroma še naprej predpisujejo način in vsebino izvajanja ureditev. Primarni problem predstavlja neprestano spreminjanje prostorske zakonodaje. 
V večini slovenskih občin še vedno veljajo določila dolgoročnih planov, sprejetih za obdobje 1986-2000 in kasneje dopolnjenih. V pripravi so skupaj s prostorskimi redi strategije prostorskega razvoja občine, predpisane v Zakonu o urejanju prostora (2002), katerega prihodnost je trenutno negotova, saj se že pripravlja nov zakonodajni dokument, tako da $\mathrm{V}$ večini občin priprava krovnih dokumentov stoji. Posebnega zakona za urbanistično planiranje v Sloveniji še nismo sprejeli, prav tako ni izdelane celovite politike, programov in načina financiranja urbane prenove.

Da bi spoznali smernice in usmeritve dosedanjega razvoja planske celote sedem, smo analizirali Odlok o ureditvenem načrtu za določitev in območje urejanja P7/1 - Nasipi (2002), veljavne prostorske ureditvene pogoje, zapisnike javnih obravnav ... in regionalni razvojni program zasavske regije, ki skupaj z Zakon o postopnem zapiranju Rudnika Trbovlje-Hrastnik in razvojnem prestrukturiranju regije Zasavje (2000), predstavlja osnovo in pomemben finančni vir prostorskih ureditev in razvojnih programov (človeški viri). Izvedena sta bila pregled angleške urbanistične zakonodaje (Zakon o urbanističnem in podeželskem planiranju - The Town and Country Planning (Local Development) (England), 2004; medmrežje 6) in analiza veljavnih dolgoročnih planov Liverpoola in najnovejših dokumentov Lokalne razvojne sheme Liverpoola (2005; Creating ... 2003).

Nekatera določila za plansko celoto sedem ne upoštevajo današnjih razmer in so povsem zastarela, na primer načrtovani izkopi in eksploatacijsko območje so veliko obsežnejši kot bodo dejansko zaradi zapiranja rudnika. V dolgoročnem planu (Dolgoročni ... 1986) so kolonije opredelili kot stanovanja v stagnaciji, v urbanistični zasnovi, sprejeti kasneje, so to že površine za stanovanja, izpraznenje zaradi preselitve prebivalcev. Dejansko se to izvaja precej počasneje od predvidenega. Kljub močno degradirani prsti so na nekdanjih rudniških površinah hkrati z rekultivacijo in renaturacijo predvideli ponovno kmetijsko rabo.

Sredstva za regionalni razvoj so se na podlagi prejšnjega RRP-ja (2001-2006) delila po treh področjih: okolje in prostor, gospodarstvo in človeški viri. Sanacija degradiranih območij sicer predstavlja eno izmed prednostnih razvojnih nalog regije, vendar so v preteklih petih letih na obravnavanem območju sredstva namenili predvsem urejanju obrtnih con Neža in Nasipi ter financiranju posameznih podjetij, ki so vlagala v izobraževanje in nova delovna mesta (9,4 \% vseh sredstev - 314 milijonov SIT v obdobju 2001-2004; Regionalni ... 2002). V celoti je v obdobju 2001-2006 največji delež sredstev namenjen za razvoj človeških virov - izobraževanje, štipendiranje, odpiranje novih delovnih mest in s tem zmanjševanju brezposelnosti (okrog 50 \% - 3,6 milijarde SIT; Regionalni ..., izvleček 2002).

Največje razlike med slovenskim in angleškim sistemom planiranja so daljša tradicija slednjega, večje in raznovrstno vključevanje javnosti, triletna ocena izvedenih dejavnosti, povezava planiranja prostora (rabe tal) in vsebine preko iniciativ za reševanje problematike urbanih območij, uveljavljene planerske institucije in manj tehnično planiranje, ki enakopravno vključuje vse prostorske vede (Marot 2005).

\subsection{Javno mnenje in mnenje strokovnjakov}

Ključni del priprave modela za urbano prenovo predstavlja analiza javnega mnenja, saj prebivalci predstavljajo dejanskega potrošnika izvedene ureditve in jih je treba zlasti v 
Sloveniji bolj upoštevati. Prispevek javnosti se je v nekdanjem sistemu skrčil le na razgrnitev že končanih načrtov, obrazložitev in na možnost zapisa mnenja prizadetih. Ker je lokalna skupnost z načrti seznanjena prepozno, jih slabo razume in se počuti odrinjena od odločanja. Zaradi tega imajo ljudje odpor do predlogov, se nanje odzivajo čustveno, okoljevarstveno in konzervativno zavračajo vse novosti. Novi zakon je z ohranjanjem starih oblik in uvajanjem prostorske konference deloma poskrbel za večjo udeležbo pri planiranju, vendar gre pri tem največkrat le za vključitev potencialnih investitorjev. Javne obravnave so podajanje mnenj javnosti in na drugi strani odgovorov pripravljavcev brez kakršnegakoli dialoga.

Socialna analiza (Pravilnik... 2004; Obrazložitev ... 2004) se pri izdelavi lokacijskega načrta predvideva le v primeru večjih vplivov na prebivalstvo, drugače se kljub njihovi dotrajanosti upošteva določila dolgoročnih planov s spremembami. Ker se je gospodarska in socialna slika jugovzhodnega dela Trbovelj precej spremenila, se je za območja, za katera še niso bili narejeni izvedbeni načrti, naredila javnomnenjska raziskava med lokalnim prebivalstvom (Vprašalniki za ostale ... 2005; Vprašalniki ... 2005).

Slika 3: Dotrajani stanovanjski objekti v Žabjeku (Naja Marot)

Figure 3: Degraded housing in Žabjek (Naja Marot)

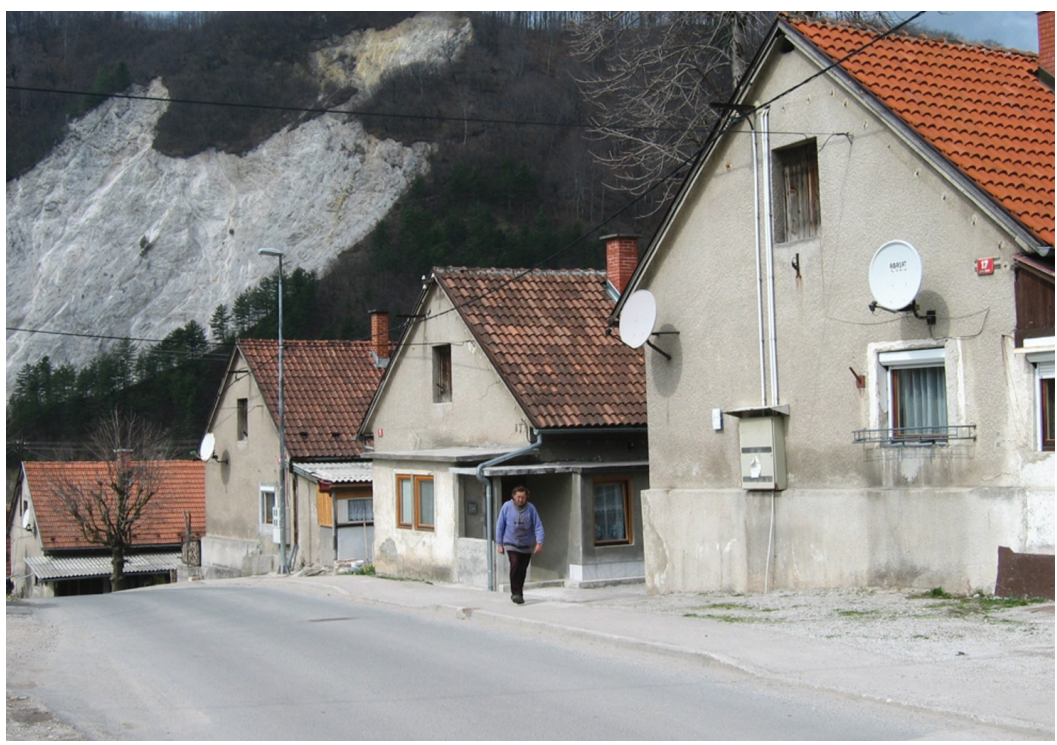

Zaradi dostopnosti širšega kroga ljudi in večje odzivnosti je bil kot najbolj primerna metoda izbran terenski vprašalnik. Z njim smo raziskali kvaliteto bivalnega okolja, poznavanje, ideje in razmišljanja o urejanju prostora, moč socialne povezanosti med prebivalci posameznih območij in dojemanje prostora v splošnem in za naš konkreten primer. Pri zasnovi vprašalnika so pomagali že izvedeni vprašalniki Benkovič (2003), Krevsa (1995), Drozga (1995), Špilar (1994) in Marot (2003). Poleg splošnih vprašanj, uporabnih za analizo kateregakoli območja, je vprašalnik vseboval tudi vprašanja, specifična le za problematiko obravnavanega 
območja. Tako so bile pokrite vse teme, ki lahko pripomorejo k zasnovi učinkovitega sistema planiranja.

Poleg obsežnejšega vprašalnika, ki je bil s časovnimi in vsebinskimi prilagoditvami izveden v Žabjeku, se je s krajšim vprašalnikom ugotavljajo tudi mnenje prebivalcev ostalih planskih celot občine Trbovlje. Zaradi ekonomičnosti izvedbe in analize je bil poslan z elektronsko pošto. Oba vprašalnika sta bila izvedena na pilotnem vzorcu. V Žabjeku je v sodelovanje privolilo 33 gospodinjstev ( $38 \%$ prebivalstva). Ker so se odgovori kmalu začeli ponavljati, tudi sicer majhen vzorec verodostojno predstavlja značilnosti pilotnega območja. Iz ostalih planskih celot/mestnih predelov je bilo pridobljeno skoraj enako število mnenj (34).

\section{Slika 4: Bukova gora - nekdanje območje površinskih izkopov (Naja Marot)}

Figure 4: Bukova gora-former surface excavation area (Naja Marot)

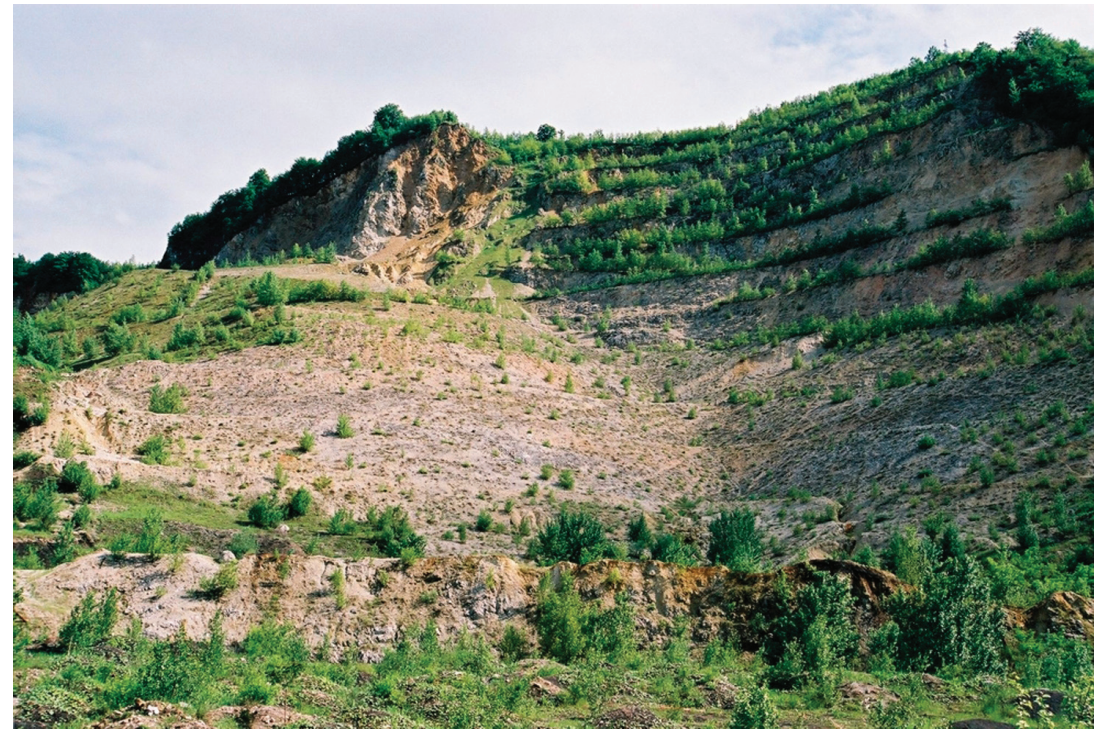

V analizi vprašalnikov se je največkrat ugotavljala frekvenca posameznih kategorij. Primerjala se je med primestnim, zgornjim (najbolj oddaljena predela od planske celote sedem), srednjim in spodnjim predelom (najbližji), da bi ugotovili, kateri predeli gravitirajo $\mathrm{k}$ planski celoti sedem in ali obstajajo kakšne razlike $\mathrm{v}$ socialni strukturi in težnje po preseljevanju. V primeru opisnega vprašanja so kot rezultat navedene vse različne možnosti. Večino odgovorov zaprtih vprašanj se da kvantificirati, kar v primeru poštne izvedbe pri večjem številu anketirancev omogoča možnost računalniške obdelave.

Poleg lokalnega prebivalstva k oblikovanju in izvedbi plana pripomorejo tudi mnenja lokalnih organizacij, uradov, podjetij in institucij. Kot najbolj primerno metodo za pridobivanje informacij akterjev planiranja je bil izbran intervju. Pogovori, s katerimi smo pridobili sliko realnega stanja prostorske dokumentacije in njenega izvajanja, obstoječih investicij in interesov 
posameznih akterjev, so bili opravljeni osebno in elektronsko od decembra 2004 do aprila 2005. Izbrana so bila mnenja občinskih urbanistov, pripravljavcev plana, podjetij z območja, upravljavca stanovanj in regionalne razvojne agencije. V povprečju je bilo zastavljenih šest do osem vprašanj z naslednjo tematiko: prostorski problemi planske celote sedem in njihovo reševanje, vključevanje prebivalstva v planerski proces, urejanje nekdanjih rudniških površin, priprava in izvajanje dosedanjih načrtov ter prostorska zakonodaja.

Predvidevanja o javnem mnenju so se v veliki meri izkazala za pravilna. Dosedaj je v Trbovljah pri javnih obravnavah kljub povabilom sodelovalo malo prebivalcev. Nepoznavanje sistema planiranja je v veliki meri odvisno od izobrazbe, ki na drugi strani ne povečuje vključevanja. Neučinkovito je delovanje krajevne skupnosti, programi, v okviru katerih bi lahko kaj storili za skupnost, ne obstajajo. Za izboljšanje prostora so po mnenju prebivalcev najbolj pristojni župan, občinski planer, krajevna skupnost, šele nato sledijo prebivalci. Nezaupanje v občinsko politiko je veliko, planiranje se smatra za povsem politično pogojeno. Zlasti akterji so poudarili večen konflikt med uporabniki in razvojniki. Prebivalstvo ni motivirano za sodelovanje, prav tako ne daje pobud in je vdano v usodo. Urejanje okolice se jim zdi še najbolj primerna in največkrat izvedena dejavnost. Zaradi odsotnosti celostnega programa razvoja prostor vsak ureja po svoje in od danes do jutri (Cvibovšek, 2005; Kropivšek, 2005; Drobež, 2005a; Tavzelj, 2005).

Izpostavljeni problemi se ujemajo s tistimi iz opredelitve značilnosti območja, na primer onesnažen zrak, neprimeren izgled stavb, nerazumevanje znotraj soseske ... in nizka kvaliteta bivalnega okolja $\mathrm{v}$ primerjavi $\mathrm{z}$ drugimi predeli. Za vzdrževanje in prenovo stanovanj kljub medsebojnim trenjem skrbijo prebivalci skupaj s stanovanjskim podjetjem. Za boljšo predstavo o vrednosti projektov: preselitev Nasipov in Hohkrautove kolonije je bila skupaj z nadomestnimi stanovanji in gradnjo ocenjena na tri milijarde tolarjev (Kus, 2005), trenutna mesečna najemnina pa znaša le 8.000 tolarjev (Drobež, 2005b). Trboveljčani planske celote sedem ne obiskujejo pogosto, bolj frekvenčni so obiski bližje živečih, ki največkrat pridejo v športno-rekreacijske namene, nekateri celo opazujejo prostorske spremembe. V Žabjeku so izpostavili zlasti problem kolonij, saj bi nekateri dotrajane objekte podrli, drugi prenovili, pri čemer največji problem predstavljajo finančna sredstva in možnost gentrifikacije oziroma reševanje stanovanjskega problema sedanjih prebivalcev.

Za upravičenost vključitve lokalne skupnosti je bistveno, da so se usmeritve lokalnega in ostalega prebivalstva prepletale in da so prebivalci podali skoraj enake usmeritve kot akterji planiranja, kar pomeni, da se jih mora v prenovo in njeno zasnovo vključiti aktivneje.

\section{PRIMER URBANE PRENOVE V LIVERPOOLU}

Po določenih izhodiščih za kompleksno prostorsko ureditev je treba določiti še smernice. Za razliko od velikih evropskih in severnoameriških mest, $\mathrm{v}$ katerih urbana prenova poteka že od sredine 60. let 20. stoletja, pri nas zaradi veliko manjšega obsega pojava, pomanjkanja razpoložljivih javnih sredstev, prakse, instrumentov urbane politike, usposobljenih kadrov in neuveljavljenosti procesa v urejanju mest temu ni tako. Povsem nasprotno ima urbana prenova v Angliji, prvi industrijski državi z največjim obsegom degradiranih urbanih območij, 
že dolgoletno tradicijo.

Na podlagi tržnega sistema planiranja so razvili podjetniško-razvojni pristop in partnersko sodelovanje javnega in zasebnega sektorja. Poleg posebne zakonodaje so uvedli številne dodatne programe: angleško partnerstvo, enotni proračun za prenovo in druge. Osnova za pristop je organiziranost lokalne uprave, kjer partnerji postopoma prevzemajo posamezne naloge, na primer pobudo za začetek, ..., predstavitev zamisli, ..., načinov financiranja in sklenitev sporazuma o izvedbi (Cullingworth, Nadin, 2002). Na občini se trije oddelki posvečajo samo urbani prenovi: oddelek za prenovo vzpostavi strateški in izvedbeni okvir prenove, programski oddelek skrbi za pridobivanje in učinkovito porabo finančnih sredstev, naloga posebnega oddelka za iniciative sta razvoj in izvedba fizične prenove in projektov (medmrežje 3). Osnovni dokument predstavlja Državni strateški izvedbeni plan revitalizacije najbolj depriviranih predelov države (medmrežje 5), dopolnjen z lokalno strategijo prenove sosesk, razvito leta 2002 skupaj s finančnim skladom in partnerji znotraj lokalnega strateškega partnerstva.

Leta 1996, ko je bil Speke Garston zaradi izgube težke industrije in drugih delodajalcev razglašen za prioritetno območje prenove, so izbrali tripartitni pristop, ki temelji na manjših timih, skupnem dostopu do finančnih virov, osredotočenosti posameznih organizacij na glavne naloge in različnih odborih. Tveganje izvedbe se je zmanjšalo zaradi delitve med tri telesa: Razvojno družbo Speke Garston (gospodarstvo in ustvarjanje delovnih mest), Partnerstvom za prenovo Speke Garston (notranje investicije in izobraževanje) in Stanovanjskim podjetjem južnega Liverpoola (prenova stanovanj in povečanje kvalitete življenja; medmrežje 7).

Med drugim je Razvojna družba Speke Garston ustanovila poslovni park, prenovila letališče Liverpool John Lennon Airport kot najhitreje rastoče regionalno letališče v EU, izboljšala lokalno infrastrukturo in dostop do delovnih mest. V prvih treh letih je zagotovila 1653 novih delovnih mest in 32,9 milijard tolarjev privatnih investicij. Celoten projekt prenove v vrednosti več kot 112 milijard tolarjev se je financiral iz občinskih in drugih javnih sredstev, sklada Enotnega proračuna za prenovo, sredstev Evropske unije Cilj 1, neodvisne javne agencije za urbano prenovo Angleško partnerstvo, investicij privatnega sektorja in posameznih iniciativ.

Januarja 2001 je vlada izdala državni strateški izvedbeni plan za revitalizacijo najbolj depriviligiranih delov države, s katerim je želela zmanjšati razlike med angleškimi najrevnejšimi soseskami in ostalim delom države, tako da v naslednjih desetih, dvajsetih letih ne bi bil nihče depriviligiran zaradi lokacije bivališča. Kot eden izmed 88 lokalnih omrežij se je leta 2002 v izvedbo državne strategije vključil tudi mestni svet in s Skupino partnerstev za Liverpool razvil lokalno shemo prenove Liverpoola. Eno izmed petih prenovitvenih območij predstavlja južni Liverpool, kamor spada tudi Speke Garston.

Skupna strategija se financira iz lokalnega sklada državne strategije za prenovo. Dokumenti iniciative v pripravi so mreža in izvedbeni plani, glavno poročilo skupnih strategij in izvedbeni plani sosesk. Strategija za južni Liverpool (South ... 2002) povezuje obstoječe plane, iniciative in programe ter vzpostavlja širši kontekst prenove sosesk.

Partnerstvo za južni Liverpool je svoje cilje opredelilo znotraj petih delovnih skupin - izobrazba, šolanje in zaposlovanje, podpora podjetništvu, lokalni skupnosti in zdravju, stanovanja in varne skupnosti. Finančni viri za izvedbo programov so sredstva Evropske 
unije Cilj 1 (28\%), privatna (37\%) in druga javna sredstva (35\%). Od 62 milijard tolarjev je največji, kar 59-odstotni delež, namenjen pripravi zemljišč.

Slika 5a, 5b in 5c: Projekti uspešne prenove na območju Speke: nova srednja šola s knjižnico in centrom soseske, novo otroško igrišče in stanovanjski blok (Naja Marot)

Figure 5a, 5b and 5c: Projects of successful renewal in Speke area: high school with library and community centre, new playing field, and housing (Naja Marot)
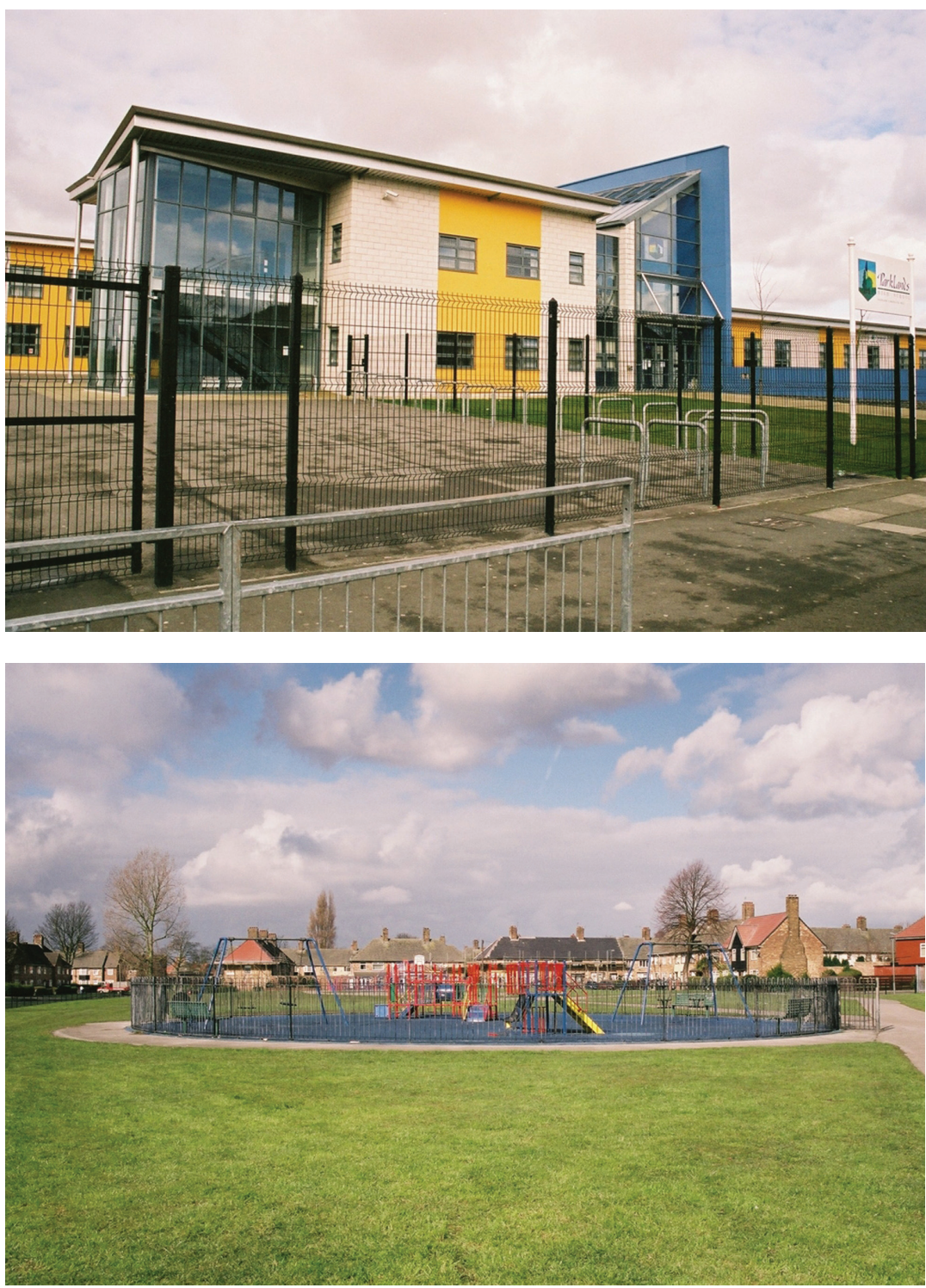


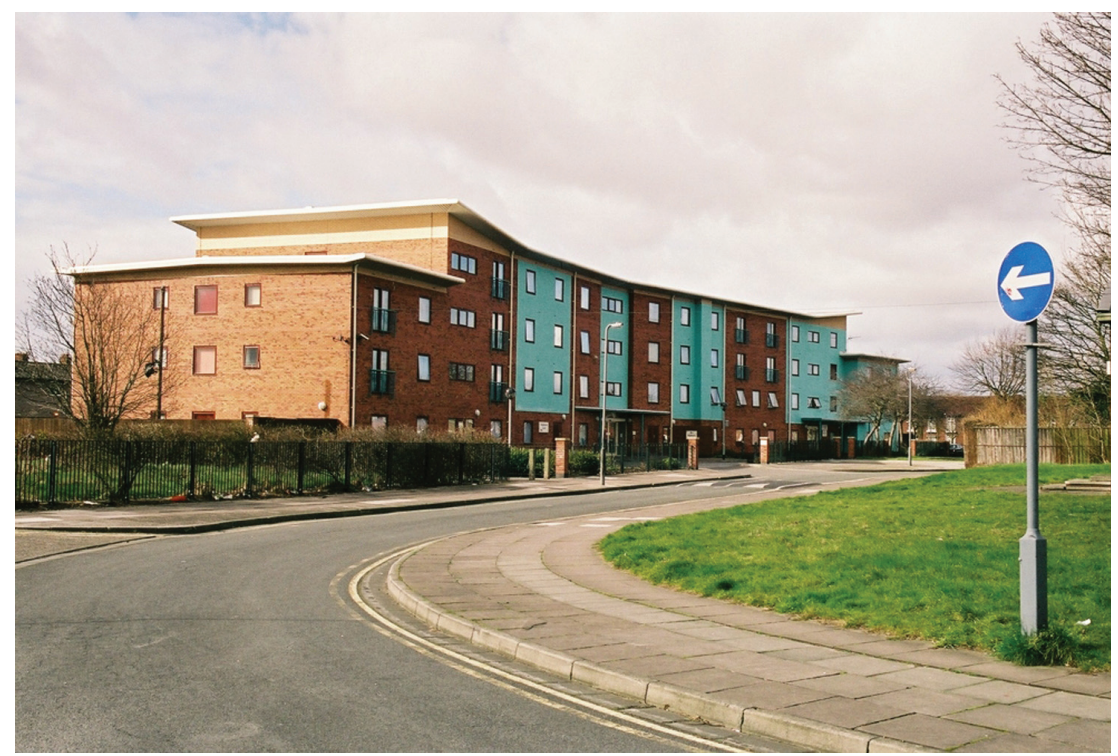

Najpomembnejše je, da vsi dokumenti in plani izhajajo iz potreb lokalnega prebivalstva, ki se je vključilo na različne načine: območna konferenca, mesečna srečevanja lokalnih organizacij, pogovori s policijo, delodajalci, prebivalci, interesnimi skupinami, javna srečanja partnerstev Speke Garstona in razprave z mestnimi svetniki. Na najnižji ravni Izvedbeni plan Speka kot prioritetne soseske (Speke ... 2002) z opredeljenimi področji potrebnimi izboljšave in posegi za dosego vladnih ciljev, združuje predloge in poglede lokalnih prebivalcev, organizacij in drugih večjih investitorjev v prihodnost Speka. Povezava z dolgoročnim planom, ki je enak slovenskemu prostorskemu planu občin, skupaj z lokalno razvojno mrežo predstavlja osnovo za prostorsko, fizično planiranje, izvedbo državne strategije in strategij partnerstev v skupnih projektih.

\section{ZASNOVA URBANE PRENOVE V TRBOVLJAH}

Na podlagi izdelane raziskave se lahko geografi povsem enakovredno vključujemo v urbanistično planiranje in zlasti veliko prispevamo na analitičnem področju in pri pripravi razvojne strategije. Glede na študijski program smo usposobljeni za delo na projektih. Oseba, ki jo je še pred začetkom urejanja planske celote sedem smotrno zaposliti na trboveljskem občinskem Oddelku za prostor in okolje samo za urbano prenovo, koordinacijo programov in njihovo izvajanje zaposliti dodatno osebo, je zato lahko prav geograf. Pri iskanju ustreznih prostorskih rešitev koristi vprašalnik, namenjen izdelavi socialne analize v urbanističnem planiranju. Z izvedbo po pošti se zaradi obsega pridobi večje število mnenj, kar omogoča, da mnenja prebivalcev postanejo ekvivalentna ostalim podlagam za izdelavo plana. 
Slika 6: Shema partnerstva za urejanje planske celote sedem

Figure 6: Partnership scheme for the development of Planning Unit Seven

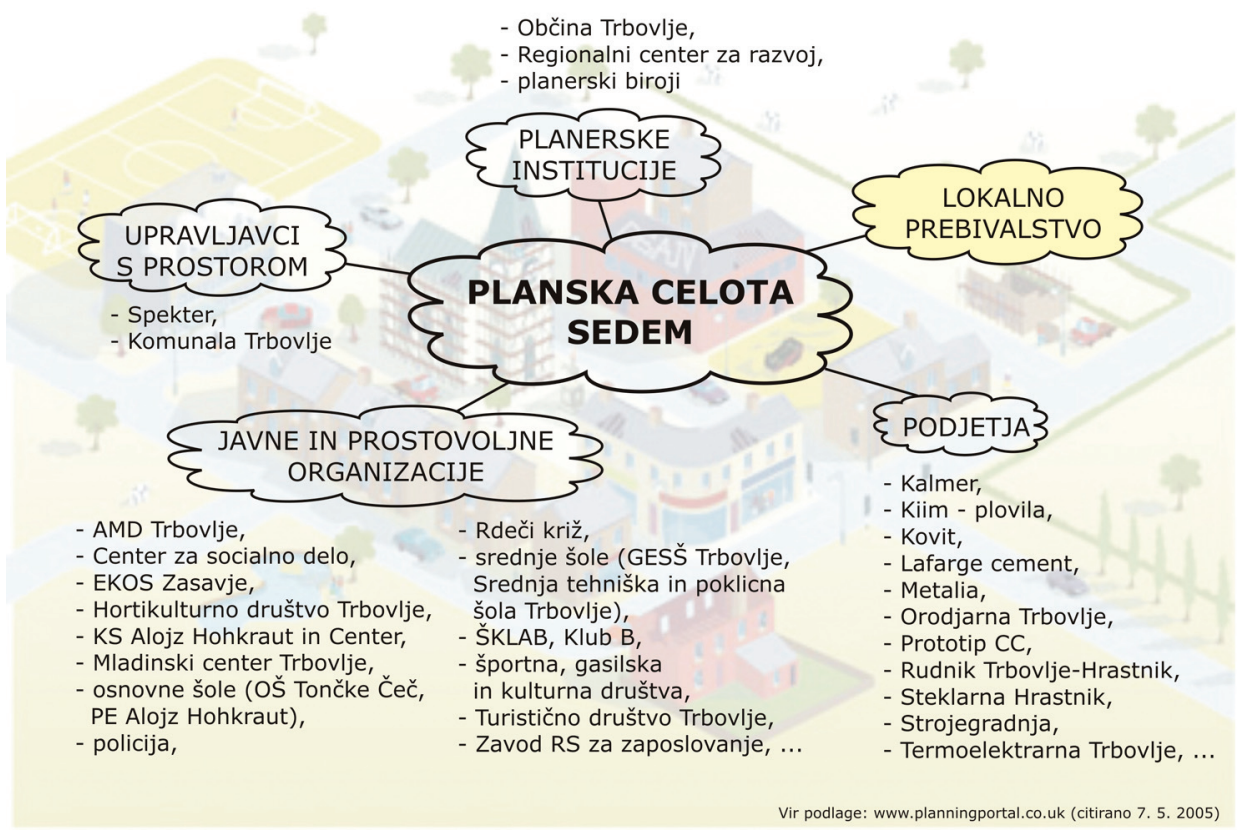

Ob sprejemu strategije prostorskega razvoja občine je treba obnoviti občinske prostorske plane, jih prilagoditi novi zakonodaji in spremenjenim prostorskim pogojem - zapiranju rudnika. Na podlagi angleškega primera je smiselno povezati prostorska določila, vsebino (urbano prenovo) in obstoječe aktivnosti na območju ter pri tem vključiti različne strokovne profile.

Optimalno rešitev predstavlja celostno urejanje $\mathrm{s}$ pomočjo partnerstva med planerskimi institucijami (občina, RRA), podjetji (Rudnik Trbovlje-Hrastnik, Cementarna, Termoelektrarna Trbovlje), upravljavci prostora (Spekter, Komunala Trbovlje), lokalnimi prebivalci in ostalimi prostovoljnimi organizacijami. K sodelovanju naj se kot opazovalce na sestankih, izvajalce terenskega dela, prostovoljce in vodje delavnic pritegne študente različnih smeri, tudi geografije, s čimer se vključi dejanske prihodnje uporabnike prostora in tudi tako zagotovi interdisciplinarnost.

Obuditi je treba delovanje KS Alojz Hohkraut in vanjo aktivno vključiti lokalno prebivalstvo, zlasti z manjšimi akcijami za izboljšanje kvalitete bivanjskega okolja. Vzporedno je treba ljudi izobraziti o planerskem sistemu in njegovih možnostih. Preko lokalnega glasila (Zasavc, Srečno), glasila, pripravljenega le za dejavnosti urbane prenove, info točk (oglasne table, splet) naj se stalno posredujejo informacije o aktivnostih na območju in poveča intenzivnost dela z marginalnimi skupinami. 
Vse to je nemogoče brez zadostnih finančnih virov. Primarna sta Zakon o zapiranju Rudnika Trbovlje-Hrastnik in razvojnem prestrukturiranju regije Zasavje in sredstva Evropske unije. Ker se slednja črpajo na podlagi regionalne politike, naj se v naslednji regionalni razvojni program za obdobje 2007-2013 kot enega primarnih ciljev vključi tudi sanacija degradiranih stanovanjskih območij. Sredstva naj prispevajo še občina, podjetja in privatni investitorji. Vlada oziroma ministrstvo za okolje in prostor mora vzpostaviti program urbane prenove slovenskih mest in ustrezne finančne instrumente zanjo, posamezna sredstva se lahko pridobi še z drugih ministrstev.

Slika 7: Smernice za prostorsko ureditev planske celote sedem Figure 7: Guidelines for the spatial development of Planning Unit Seven

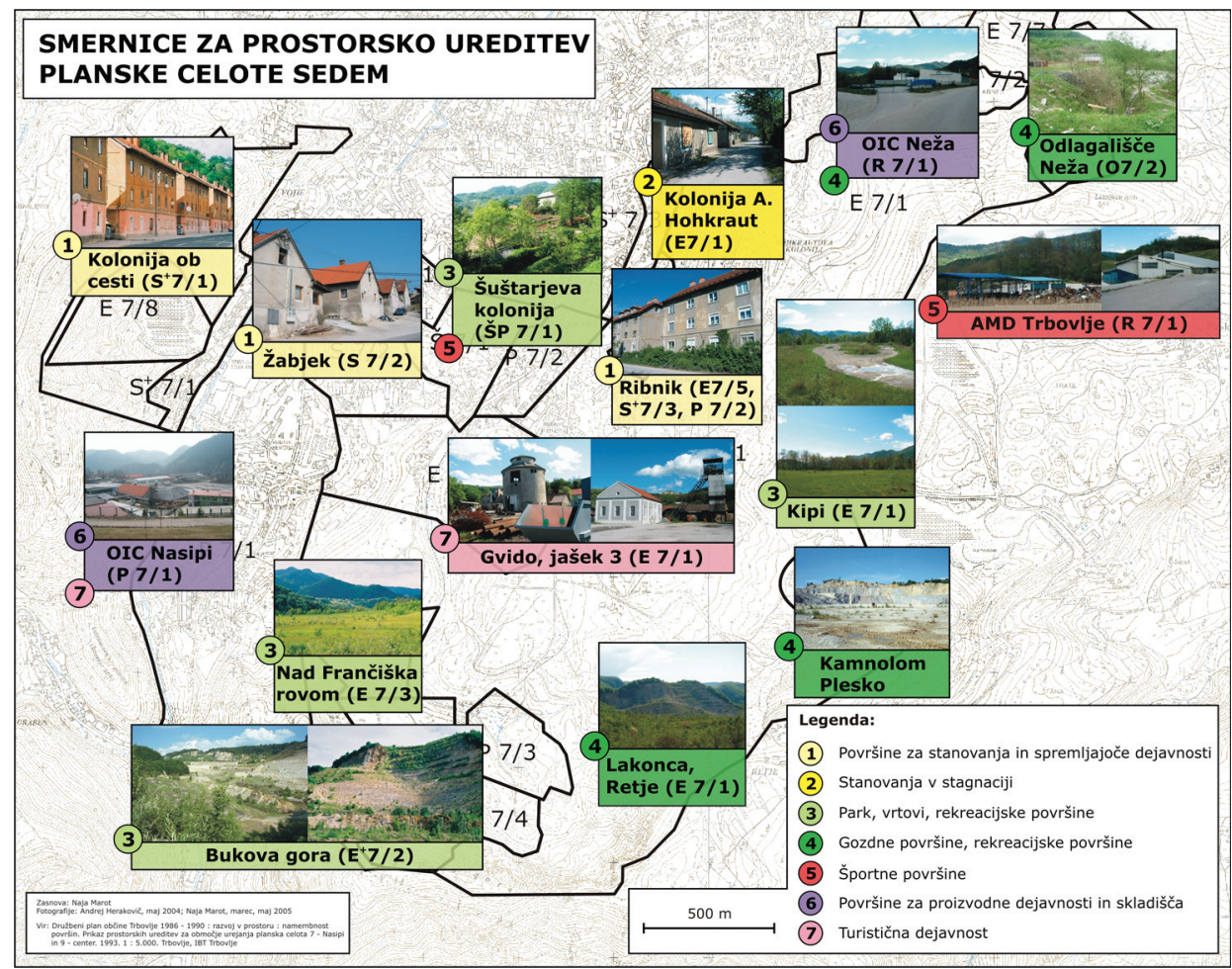

Poleg modela prenove lahko zaradi celostnega pogleda na prostor geografi podamo vsebinske smernice za prostorsko ureditev, na primer za zelene površine, oblikovanje pa prepustimo (krajinskim) arhitektom. V ugreznini pod Bukovo goro (E 7/2) naj se uredi ribnik z začasnimi gostinskimi in turističnimi objekti, na celotnem območju pa postavi informacijske table o nekdanji rudniški dejavnosti in naseljih, na uravnavi nad Frančiško (E 7/1) se predvideva parkovna ureditev. Velik del (E 7/1) bi namenili naravnim gozdnim površinam za lov, kolesarske in sprehajalne poti, na območje dodali še športni center (R 7/1), vrtove, 
zunanja športna igrišča (ŠP 7/1), renaturirali cementarniški kamnolom (Plesko) in deponijo Neža $(\mathrm{O} 7 / 2)$.

Proizvodne in storitvene dejavnosti se v bodoče izvajajo v OIC Nasipi (P 7/1) in OIC Neža (R 7/1) z okoljsko ustrezno visokotehnološko industrijo in obrtjo. Urediti je treba komunalno infrastrukturo (centralno ogrevanje/plinovod, javno razsvetljavo) in povečati število ekoloških otokov. Ustrezna postavitev parkirišč naj zmanjša promet preko območja. Ekobus naj med vikendom do posameznih točk vozi zastonj. Tehnično dediščino je treba zaščiti kot kulturni spomenik, na območje (E 7/1) prestaviti razstavo o rudarstvu iz Zasavskega muzeja in odpreti rudarsko kantino s tipično hrano po rudarskih cenah. Jamo (P 7/1) naj se priredi za krajši ogled, okoljski laboratorij pa poskrbi za študijski prikaz ekološkega izničenja površin in obnove.

Staro stanovanjsko kolonijo (S 7/2) na pilotnem območju je zaradi bližine mestnega tkiva - infrastruktura in oskrba - smiselno ohraniti. Obstoječe pritlične hiše se lahko uredi na dva načina, na primer z zglednim in celostnim vzdrževanjem - fasado v istih barvah, enakimi okni in vrati, izgradnjo infrastrukture (kanalizacija, plinovod), otroškega igrišča, odstranitvijo spremljevalnih objektov itd. Z upoštevanjem njihovih prihodkov, socialnih značilnosti je treba prebivalce povezati in urediti center skupnosti za njihovo druženje ter poskrbeti za ostarele. V vsako koloniji (S 7/1, S 7/2, S 7/3) naj se eno stanovanje obnovi kot staro rudarsko, se poveča ekološka osveščenost prebivalstva in skupaj s postavitvijo hitrostnih ovir in prometno signalizacijo uredi promet.

Podane smernice so rezultat idej prebivalcev in drugih, vključenih v razvoj. Izvedba predlaganih rešitev je brez dvoma organizacijsko in finančno obsežen projekt, izvedljiv v daljšem časovnem obdobju najmanj petnajstih let. V kolikor se pokaže volja vseh prostorskih akterjev in se kot najbolj živ element prostora vključi prav vse prebivalce, je želje po boljšem jutri prav gotovo mogoče uresničiti. Sčasoma se bo tako zgradilo zaupanje v lokalno politiko in upravljavce prostora, razvil dialog med različnimi akterji, prostor pa bo končno urejen po meri njegovih uporabnikov. K temu lahko s svojim znanjem prispevamo tudi geografi.

\section{Viri in literatura}

Benkovič, M., 2003. Strukturni problemi depopulacijskih območij v Sloveniji. Magistrsko delo, Filozofska fakulteta Univerze v Ljubljani. Ljubljana.

Creating Local Development Frameworks: consultation draft on the process of preparing Local Development Frameworks. 2003. London.

Cullingworth, B., Nadin, V. 2002. Town \& Country Planning in the UK. $13^{\text {th }}$ ed. Abingdon.

Cvibovšek, F., 2005. Urejanje rudniških površin. Trbovlje. (osebni vir, marec 2005)

Dolgoročni plan občine Trbovlje za obdobje od leta 1996 do leta 2000. 1986. Uradni vestnik Zasavja, 13, 1. 9. 1986.

Drobež, I., 2005a. Urejanje stanovanjskih območij planske celote sedem. Trbovlje. (osebni vir, februar 2005)

Drobež, I., 2005b. Značilnosti Žabjeka. Trbovlje. (osebni vir, april 2005)

Drozg, V., 1999. Nekatere dileme pri pripravi urbanistične zasnove - mariborska izkušnja. Urbani izziv 10/2. 
Drozg, V., 2005. O vključevanju javnosti v proces priprave urbanistične zasnove. Maribor. (osebni vir, marec 2005)

Državna topografska karta Republike Slovenije $1: 25.000$. 014-03-01, Trbovlje. 1997. $1: 25.000$. Ljubljana.

Gabrijel, D., 2003. Vpliv rudarjenja z vidika spremembe reliefa na preobrazbo pokrajine na območju Trbovelj in Zagorja ob Savi. Diplomsko delo. Pedagoška fakulteta Univerze v Mariboru. Maribor.

Greed, C. H., 1994. Introducing town planning. Harlow.

Greed, C., 1996. Investigating town planning. Changing Perspectives and Agendas. 1996. Harlow.

Hall, D., 2003. Images of the City. Reinventing the City? Liverpool.

Ivančič Lebar I., 1999. Naše Trbovlje. Izlake.

Jeraj, M., 2003. Urbanistične smernice za umeščanje šolskih in zdravstvenih objektov v prostor. Doktorska disertacija. Fakulteta za arhitekturo Univerze v Ljubljani. Ljubljana.

Koželj, J., 1998. Degradirana urbana območja. Ljubljana.

Krevs, M., 1995. Raziskava geografskih vidikov življenjske ravni prebivalstva: anketa za gospodinjstva, anketa za občinske župane in predsednike krajevnih skupnosti. Elaborat, Filozofska fakulteta. Ljubljana.

Kropivšek, N., 2005. Urejanje planske celote sedem. Trbovlje. (osebni vir, april 2005)

Kus, A., 2005. Priprava UN Nasipi. Trbovlje. (osebni vir, marec 2005)

Lokalna razvojna shema Liverpoola: osnutek. 2005. Liverpool.

Marot, N., 2003. Regionalna identiteta mladih v Zasavju: vprašalnik. Trbovlje.

Marot, N., 2005. Strokovna izhodišča in smernice za prostorsko ureditev na primeru degradiranega jugovzhodnega dela Trbovelj. Diplomsko delo, Filozofska fakulteta Univerze v Ljubljani. Ljubljana.

Medmrežje 1: Aktualni kazalniki: povprečna plača. 2005. URL: www.stat.si (10. 5. 2005)

Medmrežje 2: Model prenove Speke Garstona. URL: http://www.renewal.net (11. 3. 2005)

Medmrežje 3: Oddelek za prenovo. URL: www.liverpool.gov.uk/Organisation/Portfolios/ Regeneration/ (10.2.2005)

Medmrežje 4: Podatki za okrožja: popis 1981, 1991 in 2001 (UK). National Statistics. URL: www.statistics.gov.uk (10. 2. 2005)

Medmrežje 5: Strategija prenove sosesk. URL: www.liverpool.gov.uk/Business/Economic development/ (10. 2. 2005)

Medmrežje 6:The Town and Country Planning (Local Development) (England). 2004. URL: www.legislatiton.hmso.gov.uk/si/si2004/20042204.htm (16. 2. 2005)

Medmrežje 7: Model prenove Speke Garstona. URL: http://www.renewal.net (11. 3. 2005)

Medmrežje 8: Speke Garston Partnership. URL: www.sgp.org.uk (7. 2. 2004)

Medmrežje 9: Strategija prenove sosesk. URL: www.liverpool.gov.uk/Business/Economic development/ (10. 2. 2005)

Medmrežje 10: The Town and Country Planning (Local Development) (England). 2004.

URL: www.legislatiton.hmso.gov.uk/si/si2004/20042204.htm (16. 2. 2005)

Občina Trbovlje: podatki po krajevnih skupnostih, april 2001. 2001. Trbovlje. (računalniški izpis) 
Objective 1: Strategic Spatial Development Areas. Integrated Development Plan. 2000. Liverpool.

Obrazložitev Pravilnika o vsebini, obliki in načinu priprave lokacijskih načrtov ter vrstah njihovih strokovnih podlag: priloga k predlogu (23. 12. 1999). 1999. Ljubljana.

Odlok o ureditvenem načrtu za območje urejanja P 7/1 - Nasipi. 2002. Uradni vestnik Zasavja 3/22. 04. 2002.

Pogačnik, A.: 1996. Varstvo in usmerjanje oblikovne podobe slovenskih mest. Ljubljana.

Popis 1981: izbrane preglednice. 1981. Ljubljana, SURS. (računalniški izpis)

Popis 1991: izbrane preglednice. 1991. Ljubljana, SURS. (računalniški izpis)

Popis 2002: izdelane preglednice po naročilu. 2005. Ljubljana, SURS. (digitalni vir)

Pravilnik o vsebini, obliki in načinu priprave lokacijskih načrtov ter vrstah njihovih strokovnih podlag. 2004. UL RS, št. 86 / 5. 8. 2004.

Regionalni razvojni program Zasavja (2001-2006). Izvleček. 2002. Zagorje ob Savi.

Regionalni razvoj program za Zasavje. 2002. Zagorje ob Savi.

South Liverpool Partnership. Neighbourhood Renewal Strategy: Cluster Strategy 2002/03. 2002. Liverpool.

Speke Priority Neighbourhood Action Plan. 2002. Liverpool.

Špilar, Š., 1994: Socialno-ekološka problematika trboveljske doline, njena degradacija in odnos prebivalstva do nje. Diplomsko delo, Filozofska fakulteta Univerze v Ljubljani. Ljubljana.

Tavzelj, D., 2005. Urejanje planske celote sedem. Trbovlje. (osebni vir, februar 2005)

Temeljni topografski načrt. Trbovlje - G24. 1996. Ljubljana.

Urejanje prostora, graditev objektov: z uvodnimi pojasnili. 2003. Ljubljana.

Urejanje prostora in graditev objektov. 2003. Ljubljana.

Vprašalniki za ostale planske celote, 34 enot. 2005. Trbovlje. (osebni vir, marec/april 2005)

Vidergar-Gorjup, N., Batič, F., 1999. Naravne danosti, onesnaževanje okolja in stanje vegetacije na območju Zasavja. Gozdarski vestnik 57/2.

Vprašalniki za plansko celoto sedem, 33 enot. 2005. Trbovlje. (osebni vir, marec 2005)

Vrišer, I., 1963: Rudarska mesta Zagorje, Trbovlje, Hrastnik.

Ward Profile Speke; Ward Profile Series. 2004. Liverpool.

Zakon o urejanju prostora (ZUreP-1). 2002. Uradni list RS, 110.

Žilnik, P., 2002: Kolonija Njiva. Diplomsko delo, Filozofska fakulteta Univerze v Ljubljani. Ljubljana.

\section{PRACTICAL VALUE OF URBAN GEOGRAPHY IN URBAN PLANNING - CASE STUDY OF THE SOUTH-EASTERN PART OF TRBOVLJE}

\section{Summary}

After two centuries of mining, the town of Trbovlje is significantly changed. Economic, social and spatial changes are especially evident in the south-eastern part of town where the 
ground excavation started, miner's colonies were located and later on industry developed. In Slovenia, the common programme for urban renewal nor the specific legislative document have not been adopted so far. Therefore, the development of a degraded area is completely up to ad hoc solutions made in accordance with the investors' decisions. To prepare an efficient urban renewal model for our chosen area, we took a closer look at a successful English example, carried out in Liverpool, in Speke neighbourhood, to be precise. Over and above, we considered the role of geography and public participation in urban planning.

Regardless of working environment, it is the area analysis that is done first when talking about geographical work. In urban geography and planning we are interested in the town as a whole and also in its individual, functional parts. To get to know our problem areas, we made a guide overview of their spatial development and upgraded it with quantitative analysis. Statistical data show that the population is decreasing while losing youngsters and getting older. Considering the working force, unqualified (60 \% in Slovene / $53 \%$ in English case) are in majority. Since the Slovenian independence war, the minority of immigrants from former Yugoslavian republics (10\%) causes ethnic conflicts. It is significant that both residential neighbourhoods were built with the purpose of fulfiling the housing needs of population increase, caused by extreme economical raise. Housing in both areas is very poor and needs both refurbishment and renewal. Inhabitants rent (not own; 77/72 \%) flats with no central heating $(57 \% / 44 \%)$ nor baths and toilets $(16 / 0 \%)$. The infrastructure is inadequate and the renters are usually subsidized through governmental social programmes. The nature of excavation caused severe damage to the ground: the air, the soil and the water are polluted, also cracks and land-slides are evident.

With regard to the specified characteristics and urban geography theories, we can claim both areas degraded urban areas in need of immediate renewal in case the town does not want the land to lose its physical and functional development value.

When planning, we need to take into account the existing long-term state, regional, and local plans that form the legislative basis of every land development. The constantly changing spatial legislation seems to cause most difficulties and results in delays in adopting and carrying out specific urban renewal programmes. Also there is no such thing as governmental urban renewal policy or fund. Analysis of plans currently valid showed that these plans are no longer suitable for future development since the planned excavation is oversized and the development of colonies has not been specified yet.

For the last six year period (2001-2006), some improvements have been made through the regional development programme for Zasavje region and its funds. The Government has also adopted a law that sets out objectives for future regional development. So far, two enterprise zones have been developed and some other investments made in human resources.

The major difference between British and Slovenian urban planning systems is in public participation. In Great Britain, local communities present one of the most important location development facilitators and are therefore included in the whole process of planning. The methods of public participation have been widely recognized. In Slovenia, however, there is a lack of motivation for people to be involved in the planning system. The spatial law suggests different possibilities for co-operation: spatial planning conferences and public hearings. According to the query carried out in the pilot area in the south-eastern part of Trbovlje, 
people are not interested in any of them and, moreover, they also do not know much about the planning system and how it affects them. We also tried to find out what they would suggest as the most effective way of urban renewal in the area they live in, how they could interfere with it and how they evaluate their quality of life.

Beside that, we were also interested in opinions of other possible land users: inhabitants of other parts of town, and especially, in ideas for spatial development, announced by developers: major companies, housing, municipality development department and regional development office. As the most suitable method to get this additional information we chose personal interviews.

Query evaluation showed the following facts: local identity is strongly developed. As predicted, there is no accomplishment of the planning system. Locals think that local government is ineffective but also put the responsibility for urban development on the mayor, planning department, and local community. They find themselves only capable to take care of their surroundings. The most important finding of the survey is that there is no significant distinction between the locals' and planning experts' perceptions. In addition, the awareness of spatial phenomena and the understanding of its problems are very high.

On the basis of suggested solutions and the analysis of the successful urban renewal project carried out in Speke, Liverpool, we prepared the guidelines for development of Planning unit Seven, described separately for each land use. For example: former surface excavation area could be transformed into green area: partly into a park, partly into a recreational natural zone like a forest with walking and cycling paths. Finding the right solution for old colonies is not such an easy task since the authorities have to provide the same standard for the same rent which is not more than 30 Euros per month nowadays. So whichever they do, renew the buildings or pull them down, the cost will be sky-high. Ideas were also put on the final guidelines map.

With the context of the urban renewal, organisational scheme should be provided, as well. Since geographers are capable of managing projects, observing the areas as wholes, we suggest the employment of an urban renewal expert with geographical background in the municipal planning department. Spatial acts certainly need to be revised and the questionnaire carried out not only in the pilot area but also on the town level. The integral planning can only be realized through partnership that incorporates planning institutions, community and civil service, infrastructure and community management, enterprises and at last the local community as an equal partner. Getting sufficient money should not be such a problem since various financial resources are accessible nowadays. 